\title{
A travessia do tempo: a encenação da ambiguidade e a (im)possibilidade da ancestralidade em O outro pé da sereia, de Mia Couto
}

\author{
The crossing time: the staging of ambiguity and the (im)possibility of ancestry in \\ O outro pé da sereia, by Mia Couto
}

\author{
CAmila Silva Alavarce \\ GiSELE PIMENTEL MARTINS \\ Universidade Federal de Uberlândia
}

-

\begin{abstract}
Resumo: O presente estudo tem como foco analisar como, no projeto literário de Mia Couto, em $O$ outro pé da sereia, há a problematização do tempo e da ancestralidade a partir da construção estética do espaço. Há, no romance, especificamente no capítulo "A travessia do tempo", metáforas capazes de sugerir a encenação dos embates, e das rasuras deles decorrentes, provocados pela reencenação de rituais antigos no seio da família Rodrigues. Tais rasuras são explicitadas a partir de situações bastante ambíguas experimentadas pelas personagens centrais do romance, Constança e Mwadia, mãe e filha, no interior da casa materna, espaço privilegiado para servir de palco aos mais ambíguos embates. Situação esta que metaforiza a condição atual de Moçambique. Para sustentar este estudo, foram utilizados os estudiosos Assman, Halbwachs, Gama-Khalil, Bhabha, Braúna e Bachelard.
\end{abstract}

Palavras-chave: Ancestralidade; Ambiguidade; Espaço; Tempo; Mia Couto

\begin{abstract}
This study focuses on the analysis of how, the literary project of Mia Couto, in $O$ Outro Pé da Sereia, there is a questioning of time and ancestry from the aesthetic construction of space. There are, in the novel, specifically in Chapter "A travessia do tempo", metaphors able to suggest the scenario of conflicts, and their erasures arising, caused by the restaging of ancient rituals in the family Rodrigues. Such erasures are made explicit from quite ambiguous situations experienced by the main characters of the novel, Constance and Mwadia, mother and daughter, inside the mother's house, privileged space to serve as a stage to the more ambiguous conflicts. Situation that metaphorizes the current condition of Mozambique. To support this study, the works of Assman, Gamma-Khalil, Bhabha, Braunstone and Bachelard were used.
\end{abstract}

Keyword: Ancestry; Ambiguity; Space; Time; Mia Couto

"A vida são golpes, costuras e pontes. Afinal, quando Mwadia dava banho a Zero ela apenas estava costurando os tempos, dando seguimento a uma tradição antiga."

(Mia Couto)

A cena inicial do capítulo "A travessia do tempo" é bastante emblemática da discussão que proporemos neste estudo. Nela, encontramos Mwadia conduzindo o burrico Mbongolo que carregava a estátua da virgem Maria na travessia de "Antigamente" para "Vila Longe". Atravessavam o rio Mussenguezi, que correspondia justamente à fronteira entre esses dois lugares, só que "desta vez, tudo era diferente" (2011, p. 65). Desta vez, “a virgem” tinha a missão de salvar seu marido Zero. Há, portanto, uma clara retomada da mais tradicional história do nascimento de Jesus.

O que nos interessa, no entanto, é que a retomada desse tempo distante pretende salientar os remendos nem sempre visíveis - nesses diálogos entre épocas e culturas distintas, sugerindo que sempre haverá uma fissura, uma marca dessa costura entre os tempos. Assmann (2011, p. 72) comenta que as lembranças e as recordações do ser humano são acessíveis ou inacessíveis 
de acordo com os interesses do presente, sugerindo que há uma reorganização e até uma recriação dessas lembranças e das práticas a elas vinculadas - reorganização que se refere ao presente, como marca da descontinuidade entre os tempos. Logo, qualquer retomada de uma época ou de uma cultura distintas resultará numa recriação marcada pela rasura - e o projeto literário de Mia Couto parece ser pensado justamente no sentido de encontrar metáforas que explicitem a rasura.

O objetivo desse estudo é enfocar como Mia Couto, no capítulo "A travessia do tempo", a partir da construção estética do um espaço bastante cênico problematiza a questão da ancestralidade. Para a estudiosa Gama-Khalil,

(...) essa importância do espaço não se encerra apenas no plano da caracterização das personagens ou da paisagem geográfica, como um mero plano de fundo, porém, pode ser entendida como uma forma de revelar metaforicamente as práticas ideológicas do mundo posto em ficção e ser um potente canal para a deflagração de sentidos, contribuindo para o desdobramento múltiplo da polissemia literária. (GAMA-KHALIL, 2012, p. 30)

O capítulo evidencia uma relação entre espaço e tempo bastante oscilante, percebida, imediatamente, pelo seu título e pelo nome das cidades: Antigamente e Vila Longe, que sinalizam, concomitantemente, tempo e espaço. Mwadia sai de Antigamente - que é uma referência temporal, e também o nome da vila onde morava - em direção à Vila Longe, que, embora seja uma referência espacial, sugere um outro tempo. O título do capítulo, "Travessia", sinaliza espaço, mas, aqui, a personagem atravessará também tempos: "Mwadia Malunga sentiu que realmente viajava quando perdeu de vista o único casebre de Antigamente. Nunca ela pensara regressar à Vila Longe, sua terra natal." (2011, p.65) Antigamente é mostrado como um lugar sem delimitação geográfica e temporal específicas; espaço vago e tempo impreciso aparentemente anterior ao tempo-espaço de Vila Longe, também vago, porém, um pouco mais concreto, na medida em que é habitado por "pessoas vivas" e suas histórias. Logo, Mwadia atravessa tempo e espaço.

Já em Vila Longe, Mwadia chega à casa de sua mãe e, a nosso ver, esse lugar - a casa de Constança - no sentido das reflexões de Gama-Khalil, é o espaço que materializa, por meio de um trabalho estético primoroso, a discussão mencionada acima. A chegada de Mwadia ao seu destino é bastante tensa para ela. Quando atravessa o rio sente uma espécie de medo: "a mulher encheu o peito medindo forças com o horizonte." (2011, p. 66) Em outras passagens desse capítulo o medo da personagem se expressa novamente: "O ruído dos cascos do burro era a sua única defesa contra o medo. Perfilou-se perante a velha casa e um arrepio a fez estancar." (2011, p.68) Tal medo, descrito pelo narrador de maneira sutil e poética, vai se desenhando - e se tornando menos impalpável - aos olhos do leitor, no decorrer do capítulo. Mwadia parece ter medo do esquecimento e de seus desdobramentos; embora retomemos essa questão posteriormente, queremos salientar, desde já, a aproximação entre esse medo e os temas do tempo e da ancestralidade.

Falemos da casa de Constança. Para Bachelard (1978, p. 201):

(...) é necessário mostrar que a casa é um dos maiores poderes de integração para os pensamentos, as lembranças e os sonhos do homem. Nessa integração, o princípio que faz a ligação é o devaneio.

$\mathrm{O}$ passado, o presente e o futuro dão à casa dinamismos diferentes (...) A casa, na vida do homem, afasta contingências, multiplica seus conselhos de continuidade (BACHELARD,1978, p. 201 - grifos nossos).

Nessa mesma linha, Halbawachs (2003, p. 159):

A estabilidade da habitação e sua aparência interior não deixam de impor ao grupo a imagem pacificante de sua continuidade. Anos de vida comum passados num contexto a esta altura uniforme mal se distinguem uns dos outros, e se poderá duvidar que muito tempo tenha passado e tenhamos mudado imensamente no intervalo.

Halbwachs chama a atenção para o apelo de continuidade pacífica em toda a habitação e ainda salienta que os habitantes de um mesmo espaço sentem-se integrantes de um grupo uniforme, cujas diferenças individuais parecem estar dissolvidas. Bachelard, na mesma linha de pensamento, diz que o espaço da casa "multiplica seus conselhos de continuidade, afastando contingências."

O pensamento criativo de Mia Couto revela, porém, uma casa que abriga:

(...) a diversidade de crenças e atitudes, de modos de conceber o mundo e suas relações. Não há uma 'identidade' fechada, pura. Se a Nyumba-Kaya ${ }^{1}$ busca reunir, o que se reúne sob seu signo é tenso, complexo, nunca unânime ou homogêneo. E, o mais importante neste entendimento: é sempre a história (como é nas diversas outras obras de Mia Couto) que vem rasurar o que se quer dar a ver como uno, pondo em seu lugar as tensões, as humanas tramas do viver, (...) (BRAÚNA, 2014, p. 162).

Assim, a casa, em Mia Couto, abriga relações tensas, complexas, não homogêneas entre os indivíduos,

\footnotetext{
Casa do clã dos Malilanes/Marianos do romance Um rio chamado tempo, em casa chamada terra, também de Mia Couto.
} 
constituindo-se numa ambiguidade entre o abrigo-ninho e o espaço tenso das "humanas tramas do viver".

Mwadia pressente essa ambiguidade: chegará à casa-ninho, ao espaço das tensões ou a ambos? O nome da mãe de Mwadia, Constança, sinaliza que a casa é um espaço meticulosamente organizado em torno da permanência de certas práticas e rituais, - o que, de certo modo, faria de Mwadia, que estava distante, uma estranha esquecida e, da casa, um espaço tenso. No entanto, no decorrer do capítulo e do romance, o que se percebe é que a casa de Constança, ao contrário da visão dicotômica rígida, é palco dessa ambiguidade e a performatiza.

Muitos aspectos sinalizam uma tentativa de amenização de tensões, já que as normas da casa estavam consolidadas; ao visitante, cabia segui-las, o que sugere a performatização da tradição ancestral no seio familiar, situação comum nas famílias. Constança parece ser, no romance e, sobretudo, neste capítulo, uma guardiã dessas práticas familiares: não se podia falar enquanto alguém comia, porque "Quem come sozinho não se distrai com palavra" (2011, p. 70); não se podia dizer que alguém morreu, porque "no lar dos Rodrigues não se pronunciava o verbo morrer. Dizia-se: ausentar" (2011, p. 73); também não era permitido chorar, pois "chorar era um malfazejo hábito que se espalhara como doença. Eles, os Rodrigues, não choravam" (2011, p. 73). Alguns desses ritos parecem um modo de amenizar a tensão, como se pode ver na cena em que o marido de Constança está triste porque sua irmã morreu, e quer contar à esposa:

- Tem uma notícia triste, marido?

- Muito triste.

- Então, já sabe como me vai contar.

Ela deitou-se, despiu-se e esperou que o marido se enroscasse a seu lado. Depois beijou-o e abraçou-o com força. Enquanto faziam amor ele lhe foi contando a novidade da morte de Luzmina, desfiando a tristeza que a mulher ia sufocando a golpes de ternura, corpo diluindo-se em outro corpo (2011, p. 77).

Dar a notícia de uma tragédia fazendo amor parece é o rito a ser encenado. Curioso notar que o sexo, por si mesmo, já é bastante ambíguo, uma vez que materializa uma tensão entre violência e carinho. Logo, se, por um lado, há o acolhimento típico das práticas sexuais - até porque o marido deixa fluir a sua tristeza por meio do choro e das palavras - há também, a imposição desse ritual. Outro aspecto importante é o elemento catártico do sexo nesta cena: fazer amor, aqui, significa potencializar fortes emoções, vivenciá-las numa tentativa desesperada de exorcizá-las, mas sem poder discuti-las.

Como já exposto, as normas da casa de Constança e especialmente a manutenção dessas normas estão atreladas a essa personagem, que determina o cumprimento desses ritos, de forma que parece não haver discordâncias nesse espaço. Mwadia, sua filha que está voltando para casa - vinda de Antigamente - representa uma espécie de ameaça a todas essas regras pré-estabelecidas e perpetuadas. Afinal, ela estava fora, e, ao chegar à Vila Longe, se sente "(...) como se ela, mesmo regressando, se mantivesse ausente" (2011, p. 68).

Para além de um clássico embate de gerações, marcado por um estranhamento previsto entre filhos que retornam ao espaço da casa paterna, há, neste capítulo, a partir da construção estética do espaço, uma discussão cara à literatura africana - discussão que perpassa a problematização do conceito de ancestralidade e de seus rituais. $\mathrm{O}$ desconforto entre mãe e filha, neste capítulo, insinua-se em muitos momentos. Elas se encontram quando Mwadia, percorrendo o corredor escuro da casa, avança com dificuldade e subitamente "embate num vulto escuro" (2011, p. 72 - grifos nossos), que é a sua mãe doente e que "duplicara de volume", porque "a tristeza engorda mais do que o caril de mandioca" (2011, p. 72). E, entre as duas, os "embates" se efetivam: Mwadia não pode chorar a morte da tia Luzmina, nem pode dizer que a tia "morreu". Pergunta à Constança: "Por que é que a mãe nunca me visitou?" (2011, p. 73) e obtém como resposta: "Não fui eu que saí de casa" (2011, p.73). Constança mostra à filha a última fotografia tia Luzmina, tirada pouco antes de sua morte:

A mãe não disse mais, apenas soergueu o queixo a pontar o corredor. Mwadia sabia do seu dever. Pegou na imagem e conduziu-a à chamada 'parede dos ausentes'. No corredor exibiam-se as fotos dos familiares defuntos. No chão, um balde recolhia as lágrimas dos falecidos (2011, p. 74 - grifos nossos).

Ao entrar na casa de Constança, Mwadia se vê, pois, cercada de práticas que precisam, necessariamente, ser obedecidas, e a sua chegada a esse espaço é tensa, como já dissemos: "Empurrando o saco de viagem pelo chão, Mwadia avançava a custo" (2011, p. 72). Muito significativa a metáfora do "saco de viagem", afinal nele se encontra o que Mwadia traz de Antigamente, aquilo que é estranho a esse espaço/tempo, e que é carregado "a custo". Logo, Mwadia parece temer, justamente, a sua excentricidade em relação a esse espaço - aparentemente organizado social, emocional e psicologicamente de maneira rígida - e diante do qual ela acaba representando $\mathrm{o}$ inesperado, o adverso.

Depois de passarem pela "parede dos ausentes", a mãe decide: "- Agora, venha, disse a mãe. Venha que eu vou lavá-la. - Lavar-me? - Quero que seja você, sozinha com seu corpo, a entrar nessa casa (2011, p. 74). Esse diálogo é bastante sugestivo dessa discussão que estamos 
propondo. Mwadia saiu de casa, como faz questão de lembrar a sua mãe. Logo, Mwadia esteve fora desse espaço todo construído e organizado em torno de determinadas práticas ancestrais familiares. Sente, portanto, medo de não pertencer mais a esse lugar. Importante lembrar que a filha de Constança não compartilha mais o sobrenome Rodrigues, da família: ela é Mwadia Malunga, aquela que partiu e que agora retorna. Constança, de certo modo, legitima essa sensação de inadequação vivenciada pela filha, sobretudo quando decide lavá-la: "As mãos da mãe fizeram escorrer a água pelo corpo nu de Mwadia. (...) Fechou os olhos, embriagada, como se a alma estivesse sendo dissolvida." (2011, p. 74)

É importante perceber o que dissemos anteriormente: a ambiguidade que permeia as possíveis leituras que podemos fazer desses embates sutis entre a mãe e a filha. De um lado, o comportamento de Constança é compreensível, no sentido de acolher a filha que voltou para casa. Mwadia se entrega a esse rito ordenado pela mãe, que "perdeu" as filhas e que tenta retomá-las, recolocá-las naquele espaço e reencontrá-las como elas eram antes, num passado já distante, de convívio - o passado da infância, talvez:

A mãe suspendeu o gesto e apontou para a cozinha exterior. E confessou que, às vezes, ela ia para ali sentar-se só para reviver os tempos em que a família se arredondava, no grávido círculo da felicidade.

- Vou para ali só para sentir saudade.

- E gosta?

- A saudade é a única dor que me faz esquecer as outras dores. (2011, p. 75)

Por outro lado, é preciso notar o matiz opressor dessa mãe, que parece se sentir ameaçada pela chegada da filha; para Constança, não importa saber o que Mwadia traz desse período em que esteve ausente, tampouco se a filha acredita naquelas práticas e se deseja retomá-las - bem ao encontro da cena de sexo entre Constança e o marido, na qual também não cabiam diálogos. É como se Mwadia precisasse se despir de quem é, nesse momento, para ser acolhida na casa de Constança, sua mãe e, mais que isso, para caber no espaço afetivo das lembranças que a mãe guardava da filha.

O banho representa esteticamente essa ambiguidade tão delicada - a linha tênue - entre o cuidar e o coagir, afinal, lavada pela mãe, Mwadia "fechou os olhos, embriagada, como se a alma estivesse sendo dissolvida" (2011, p. 74 - grifos nossos). Terminado o banho, Mwadia "deixou-se levar para o quarto e a mãe esfregou-a numa toalha velha. Tudo parecia perfeito, Mwadia era de novo menina e os beirais se enchiam de asas e cantos" (2011, p. 75 - grifos nossos).

Voltando ao tema do medo vivenciado por Mwadia:
Quem parte treme, quem regressa teme. Tem-se medo de se ter sido vencido pelo Tempo, medo de que a ausência tenha devorado as lembranças. A saudade é um morcego cego que falhou o fruto e mordeu a noite (2011, p. 68)

Mwadia "ansiava recuperar o sentido de pertença a um lugar. Ela estava, a um tempo, receosa e ansiosa." (2011, p.68) Já diante da casa materna: "Perfilou-se perante a velha casa e um arrepio a fez estancar. A casa da infância é como um rosto de mãe: contemplamo-lo como se já existisse antes de haver o Tempo" (2011, p. 68).

A casa da infância - atemporal como um rosto de mãe - constrange Mwadia. Importante salientar, mais uma vez, a ambiguidade que permeia a relação de Mwadia com a casa e com a mãe: não sendo mãe, Mwadia não pertence a esse lugar atemporal primeiro do qual todas as mães e suas casas parecem fazer parte; por outro lado, como filha, fica mais suscetível aos rituais de acolhimento da mãe. Logo, Mwadia é estranha por não ser mãe, mas também - "somente" como filha - cria uma condição natural de afinidade com o espaço da casa e com a mãe - "lugares" aptos a recebê-la exclusivamente como filha, papel que lhe é familiar e lhe dá prazer.

Como dissemos, o constrangimento dessa personagem (constrangimento também de Constança) passa pela questão do tempo e do medo do esquecimento. Afinal, de que esquecimento estamos falando? Conforme Bhabha prevê (2013, p. 21):

Ao reencenar o passado, este introduz outras temporalidades culturais incomensuráveis na invenção da tradição. Esse processo afasta qualquer acesso imediato a uma identidade original ou "recebida". Os embates de fronteira acerca da diferença cultural têm tanta possibilidade de serem consensuais quanto conflituosos;

Mwadia sabe-se mudada pelo tempo e sabe da necessidade de se aceitar esse movimento natural de mudança que caracteriza a vida. Ela pergunta ao seu marido: "- Porquê, Zero Madzero, por que é que eu recordo tanto?" (2011, p.68). E o narrador nos diz que "o marido não sabia responder. Era por isso que ela lhe perguntava: por não temer a resposta. No íntimo de si, Mwadia sabia: quem se lembra tanto de tudo é porque não espera mais nada da vida." (2011, p.68) Fica claro o diálogo entre Bhabha e a percepção que Mwadia tem da temporalidade e de suas reencenações que - como reencenações - introduzem sempre novos matizes, novas possibilidades. Para Mwadia, lembrarse muito é não esperar mais nada da vida, ou seja, estar morto. Tendo em mente essas reencenações, Halbwachs considera: 
É comum falar-se em "tempo históricos" - como se houvesse muitos, e talvez com isso designássemos períodos sucessivos, mais ou menos distantes do presente. Contudo, também podemos dar um outro sentido a essa expressão, como se houvesse muitas histórias, distintas, umas começando mais cedo, outras começando mais tarde. Claro, um historiador pode colocar-se fora e acima de todas essas evoluções paralelas e considerá-las como outros tantos aspectos de uma história universal. Sentimos também que, em muitos casos, talvez até com frequência maior, $a$ unidade que obtemos então é completamente artificial, porque assim aproximamos acontecimentos que não tiveram nenhuma influência uns sobre os outros e povos que não se baseavam, sequer temporariamente, em um pensamento comum (2003, p. 129 - grifos nossos).

No sentido de Halbwachs, Mwadia tem noção de que não compartilhamos uma "história universal": sabe-se outra, distante daquela que deixou a casa materna e foi embora para Antigamente. Mwadia sabe, enfim, que a ideia de uma "unidade" de pensamento entre ela e a sua família de origem é "artificial". A consequência imediata é justamente Mwadia temer o esquecimento e a sua provável consequência: o não pertencimento.

Esquecimento dos velhos rituais encenados no espaço da casa materna; esquecimento de sua antiga identidade, quando fazia parte daquele espaço, como filha de Constança. Mwadia ainda teme que, ao chegar à casa de sua mãe, se esqueça de quem ela é - nesse presente da narrativa -: a mulher adulta que retorna, já estranha àquele espaço. Importante notar que o esquecimento, palavra normalmente associada a uma ideia de passado, sofre, aqui, um deslocamento: além de projetar-se no presente da narrativa - representando o medo de Mwadia de perder-se, de esquecer-se de sua identidade "atual" projeta-se ainda para o futuro, no sentido de que - presa ao passado - Mwadia fatalmente se esqueceria de seu futuro.

Subjaz a toda essa construção estética marcada, como vimos, pela presença do poético, uma crítica sutil e delicada - no entanto, decisiva - ao entendimento mais tradicional do conceito de ancestralidade. Para Assmann (2011, p. 70), “(...) definimo-nos a partir do que lembramos e esquecemos juntos. Reformulação da identidade sempre significa também reorganização da memória, o que também vale, como bem sabemos, para a comunidade e não menos para indivíduos." E, ainda,

As recordações estão entre as coisas menos confiáveis que um ser humano possui. As respectivas emoções e os motivos de agora são guardiães do recordar e do esquecer. Eles decidem que lembranças são acessíveis para o indivíduo em um momento e quais delas permanecem inacessíveis $(2011$, p. 71-72).
Logo, o projeto literário de Mia Couto no romance "O outro pé da sereia" - projeto que se evidencia, sobretudo, no capítulo "A travessia do tempo" - lança um olhar desconfiado para a questão das práticas ancestrais, retomadas nesse capítulo por meio dos rituais da família Rodrigues. Olhar desconfiado no sentido de problematizar essa questão por meio de uma construção estética ambígua, projetada para ser o palco dessa encenação acerca do tempo, da ancestralidade e suas práticas e da impossibilidade do futuro, se considerarmos o apego ao entendimento tradicional do conceito de ancestralidade.

Nesse sentido, a construção do espaço da casa de Constança nos parece o "gatilho" para toda a discussão proposta pelo autor. Mais uma vez, com Bachelard: "Em seus mil alvéolos, o espaço retém o tempo comprimido. O espaço serve pra isso. (...) É pelo espaço, é no espaço que encontramos os belos fósseis de uma duração concretizados em longos estágios" (1978, p. 202-203, grifos nossos). Assim, seja nas palavras interditadas na casa de Constança; seja na ambiguidade do banho que ela dá em Mwadia; seja, ainda, no tradicional costume de amenizar a dor por meio de alguns ritos que se situam no entrelugar "cuidado"/imposição; em todas essas regras perpetuadas pelos Rodrigues, o espaço tem uma função estética fundamental.

Há outra cena bastante simbólica no sentido em que estamos orientando a nossa discussão: a passagem de Mwadia pelo corredor que dá acesso ao interior da casa. Como já mencionado rapidamente, esse corredor abriga a "parede dos ausentes", onde estão penduradas as imagens dos familiares falecidos e - mais que isso em cujo chão, bem abaixo das fotografias, há um balde recolhendo as lágrimas dos "ausentes". Perguntamo-nos: por que choram esses mortos? Por estarem fadados ao esquecimento, por aquele já mencionado movimento natural de transitoriedade do tempo e da vida? Ou porque não podem, de fato, morrer, convocados que estão por essas práticas familiares ancestrais?

De todo modo, as imagens dos falecidos chorando - situadas nessa passagem inevitável para a parte mais interna da casa (o corredor) - não deixam de ser um meio de dizer, àquele que entra, qual é o "lugar" e o tratamento recebido pelos mortos no espaço da casa de Constança. Nela, os mortos são lembrados: tão lembrados que estão, de certo modo, vivos, já que envelhecem nas fotografias:

Mão na mão, as duas mulheres percorreram as linhas do rosto da falecida Luzmina, como se lhe corrigissem o destino. Alinhavam a moldura na parede como quem ajeita flores sobre uma campa.

- Que idade ela tinha nesta foto?

- Tinha não. Tem.

- Não entendo. 
- Essa foto ela tirou-a com trinta e cinco anos. Mas a sua Tia continua a envelhecer na imagem.

- Ora, mãe...

- A última vez que peguei nessa foto ela nem tinha estes cabelos brancos... (2011, p. 78).

$\mathrm{Na}$ casa, os mortos choram. Nela são respeitados, e suas lágrimas recolhidas. Quem atravessa o corredor é persuadido a compactuar: não só pelo apelo emotivo do choro - mas especialmente por configurar-se o corredor como um espaço poético, simbólico, causador de catarses nos passantes. Impossível entrar, de fato, na casa sem atravessar o corredor, espaço representativo de um pensamento criativo que almeja rediscutir, encenando, de maneira sempre ambígua, o conceito tradicional de ancestralidade - afinal, nesse lugar de passagem para o interior da casa, os mortos estão vivos; vivos não do modo como estiveram vivos em seus "últimos" dias. Estão vivos e envelhecendo - mudando - o que sugere justamente a rasura ou a costura entre os tempos.

O passado original, tal como se constitui, é incapturável, já que inevitavelmente se "contamina" pelo olhar-outro do presente - e muda. Logo, a construção estética desse espaço específico da casa de Constança é também palco para a encenação das questões discutidas neste estudo. Lançando um olhar mais demorado para a revisitação do conceito de ancestralidade, podemos pensar o seguinte: se, na parede do corredor da casa de Constança, os mortos estão vivos porque envelhecem, porque choram, qual seria a diferença especificadora entre o que morreu e o que está vivo, ou seja, entre passado e presente?

Nesse e em outros momentos da narrativa, Mia Couto parece almejar a diluição das fronteiras entre os tempos - diluição anunciada, inclusive, nos títulos dos espaços habitados pelas personagens: Antigamente e Vila Longe, que sinalizam, temporalmente, algo vago; afinal, imaginamos que Antigamente esteja mais distante temporalmente em relação à Vila Longe, no entanto, o quanto mais distante? A própria organização do romance, num vai e vem entre tempos e espaços, é significativa nesse aspecto: narram-se fatos do ano de 1560, em Goa, e do ano de 2002, em Moçambique - informações espaço-temporais que estão na entrada do capítulos; há, ainda, o capítulo 5, que se situa num "Tempo indeterminado na actualidade." Essa estrutura narrativa sugere a proximidade ou o diálogo inerentes a esses tempos e, logo, uma espécie de diluição de fronteiras, como se passado e presente coexistissem naturalmente.

Se os mortos estão chorando e envelhecendo nas paredes, não há, nessa construção poética, quebra brusca ou diferença singularizadora entre vivos e mortos. Por conseguinte, o pensamento criativo de Mia Couto sinaliza, em lugar de um passado originário e imutável ou morto - que precisaria ser ritualizado assim - um passado que, por um movimento espontâneo, chega ao presente e vive, nele, modificado (o passado) e modificando (o presente) e por que não, o futuro?

Nesse sentido, não estaria o escritor moçambicano pondo em relevo um mover-se natural do passado para o presente ou ainda, ao contrário, do presente para o passado, dando a ver - de todo modo - o óbvio e esperado diálogo entre os tempos? Não estamos diante de um projeto literário que almeja retirar de Moçambique essa "especificidade ancestral", tentando resgatar, nesse país, o que é seu por direito: um presente e um futuro - ao mostrar que a movência do passado para o presente e, ainda, as rasuras e costuras resultantes desses diálogos estão presentes, caracterizando qualquer sociedade em que haja vida?

A proposta estética encenada no romance e, em especial, no capítulo objeto desta análise, cujo foco são os embates no interior da casa de Constança, faz ver poeticamente a peculiar situação de Moçambique e possivelmente de outros países africanos. Olhando pelo buraco da fechadura da casa, o que se vê é um conflito muito ambíguo e muito velado que, no entanto, centraliza-se numa questão cara à contemporaneidade moçambicana e africana: a tensão entre o culto ao passado e a natural intervenção do presente. Nas palavras de Mia Couto,

(...) Quer dizer, África não está só perdendo o seu próprio presente: está perdendo o chão onde nasceria um outro amanhã.

Ter futuro custa dinheiro. Mas é muito mais caro só ter passado.

(...) A pergunta crucial é esta: O que nos separa desse futuro que todos queremos? (...) para mim há outra coisa que é ainda mais importante. Essa coisa tem um nome: é uma nova atitude. Se não mudarmos de atitude não conquistaremos uma condição melhor. (2009, p. 18)

Como se vê, Mia Couto não apenas tece esteticamente, como projeto ficcional, a discussão em torno da ancestralidade africana, mas também reflete teoricamente sobre esse assunto, em conferência realizada em Maputo, em 2006 (2009, p. 18) - revelando veementemente a sua atitude em relação à construção de um novo futuro para Moçambique. Em outra conferência, em Estocolmo, no ano de 2008, o escritor rejeita o que chama de "folclorização" (2009, p. 14) do presente a partir de um passado construído "fora do continente" (2009, p.14). Mia Couto ainda chama a atenção para o fato de que 
(...) Os escritores africanos sofreram durante décadas a chamada prova de autenticidade: pedia-se que os seus textos traduzissem aquilo que se entendia como sua verdadeira e etnicidade... Os escritores africanos desejam ser tão universais como qualquer outro escritor do mundo (2009, p. 11).

Portanto, sendo Mia Couto um dos escritores fundadores do "cânone" moçambicano contemporâneo, é visível, em $O$ outro pé da sereia, a preocupação deste escritor com o presente e com o futuro do Moçambique, sugerindo que o passado, o antigamente, deve ficar no lugar dele, para que o presente seja reconhecido e o futuro aceito. Caso contrário, corre-se o risco de ficar como Mwadia, em Antigamente, vivendo com Zero Madzero, morto, ou seja, viver numa Moçambique morta, que já não existe, mas que acaba condicionando o comportamento dos moradores (e dos olhares externos) para a perpetuação de discursos e práticas anacrônicas, que negam o presente e impedem o futuro.

Finalmente, é irônico pensar que Mwadia, vinda de Antigamente, acaba por representar uma possibilidade de se colocar em xeque hábitos e costumes ancestrais da família Rodrigues - hábitos do presente dessas pessoas. A proposta de problematização do conceito de ancestralidade não estaria, também, metaforizada na construção estética da personagem Mwadia? Afinal, vinda de Antigamente (espaço), não estaria ela encenando os próprios rituais do passado, que vêm de antigamente (tempo) e, exatamente por virem daí, não caberiam mais no presente - tal como eram - tornando-se estrangeiros deslocados ou, simplesmente, anacrônicos, nesse tempo presente?

\section{Referências}

ASSMANN, Aleida. Espaços da Recordação. Campinas: Editora da Unicamp, 2011. (Tradução Paulo Soethe).

BHABHA, Homi K. O Local da Cultura. Belo Horizonte: Editora UFMG, 2013. (Tradução de Myriam Ávila, Eliana Lourenço de Lima Reis e Gláucia Renata Gonçalves).

BACHELARD, Gaston. "A poética do espaço". In: A filosofia do não; $O$ novo espirito científico; $A$ poética do espaço. São Paulo: Abril Cultural, 1978 (Os pensadores).

BRAÚNA, José Dércio. Nyumba-Kaya: Mia Couto e a delicada escrevência da nação moçambicana. São Paulo: Alameda, 2014.

GAMA-KHALIL. Marisa Martins. "As teorias do fantástico e sua relação com a construção do espaço ficcional.” In: Vertentes teóricas e ficcionais do insólito. Organização: Flavio García, Maria Cristina Batalha. Rio de Janeiro: Editora Caetés, 2012.

HALBWACHS, Maurice. A memória coletiva. São Paulo: Centauro, 2003 (Tradução de Beatriz Sidou).

MIA COUTO. E se Obama fosse africano? Companhia das Letras: São Paulo, 2009.

MIA COUTO. O outro pé da sereia. São Paulo: companhia das Letras, 2011.

Recebido: 30 de abril de 2016 Aprovado: 29 de agosto de 2016 Contato: camilaalavarce_ufu@yahoo.com.br gipimarti@gmail.com 